\title{
Ultrasound as a bedside tool for diagnosis of post-intubation tracheal stenosis
}

\author{
Shereen Farghaly ${ }^{1 *}$, Ashraf Zin El-Abdeen ${ }^{1}$, Lamiaa H. Shaaban ${ }^{1}$, Hossam El-Deen Galal M. El-Malah² and \\ Maida Kamal ${ }^{1}$
}

\begin{abstract}
Background: Screening of post-intubation stenosis can allow early diagnosis, early management of stenosis, and possible prevention of progress. Fiberoptic bronchoscope is the gold standard for diagnosis of tracheal stenosis. Other imaging modalities as computed tomography can be considered but are not available in intensive care unit.

Purpose of the study: To evaluate the validity of ultrasound (US) as a bedside test for early diagnosis of postintubation stenosis compared to multidetector computed tomography (MDCT) and fiberoptic bronchoscope (FOB).

Results: Out of the 50 included patients, 12 patients were found to have definite stenosis by FOB. Compared to CT, significant positive correlation was found between all ultrasound parameters (laryngeal width, tracheal diameter) and corresponding CT parameters ( $r=0.798, p<0.001 ; r=0.714, p<0.001$ respectively). Compared to FOB results, the yield of MDCT chest for diagnosis of stenosis had $91.6 \%$ sensitivity and $100 \%$ specificity, while the yield of US detected by mucosal irregularity as a diagnostic tool for tracheal stenosis had comparable sensitivity (91.6\%) but lower specificity (88.9\%).
\end{abstract}

Conclusion: Due to its high sensitivity, US could help in detection of possible post-intubation laryngotracheal stenosis in critically ill MV patients.

Keywords: Mechanical ventilation, Ultrasound, Post-intubation stenosis

\section{Background}

Endotracheal intubation is commonly used for respiratory support in an intensive care unit (ICU) [1]. Tracheal stenosis is the most crippling complication of endotracheal intubation. The reported incidence of postintubation stenosis ranges from 10 to $22 \%[2,3]$.

The diagnosis of post-intubation stenosis is often late and difficult to draw on the simple clinical conception because the clinical signs are not necessarily typical [4]. Bronchoscopy is considered the "gold standard" for diagnosis of tracheobronchial pathology; however, it is difficult to be applied in intubated patients [5].

Conventionally, airway imaging has been done with Xray, MRI, and CT scan which are expensive, high

\footnotetext{
*Correspondence: shereen@aun.edu.eg

${ }^{1}$ Chest Department, Faculty of Medicine, Assiut University Hospital, Assiut, Egypt

Full list of author information is available at the end of the article
}

ionizing modalities, and are not easily available in ICU [6]. Recently ultrasound has been applied broadly on critical care $[7,8]$. Sonography as a bedside modality represents an ideal imaging modality for evaluation of tracheal emergencies [9].

The study aims to evaluate the validity of airway ultrasound for diagnosis of post-intubation tracheal stenosis, compared to multidetector computed tomography with virtual bronchoscopy and fiberoptic bronchoscopy among mechanically ventilated patients.

\section{Methods}

This prospective cohort study was conducted at the Respiratory Intensive Care Unit, Department of Chest Diseases and Tuberculosis, Faculty of Medicine, Assiut University Hospital over 2 years period (from June 2016June 2018). An informed consent was obtained from patient relatives before their inclusion in the study. The 
study was approved by the Medical Ethics Committee of Faculty of Medicine Assiut University Hospital.

\section{Inclusion and exclusion criteria}

Patients underwent endotracheal intubation with mechanical ventilation due to respiratory failure for $48 \mathrm{~h}$ or more. Patients below 16 years old, those known with airway complications due to previous intubations, those with tracheostomy, those with enlarged thyroid gland, or those with malignant growth of the airways were excluded from the study. To be included in result analysis, patients should be proceeded to upper airway ultrasound, MDCT chest, and fiberoptic bronchoscopy (FOB).

\section{Study design}

Patients were assessed clinically, by ultrasound, by computed tomography, and by FOB. FOB results were taken as the gold standard for the diagnosis of laryngotracheal stenosis.

\section{Careful history taking and examination}

In this study, detailed history and examination was done to evaluate demographic data, underlying chest diseases, cause of admission in RICUs, history of previous intubation, body mass index (BMI), and APACHE II score.

\section{Upper airway ultrasound}

Airway ultrasound (Samsung Medison Sono Ace R3 ultrasound system; Samsung Company, Seoul, South Korea) was performed to all patients during the $1 \mathrm{st} 48 \mathrm{~h}$ of mechanical ventilation and at time of extubation. Laryngeal US was used to visualize the vocal cords and measure air column width (ACW). The examination was done while patients were in a supine sniffing position ventilated by assist-control mode with $5 \mathrm{~cm} \mathrm{H}_{2} \mathrm{O}$ of positive endexpiratory pressure. The patients' endotracheal and oral secretions were gently suctioned. The $5.0 \mathrm{MHz}$ linear probe was placed on the cricothyroid membrane with a transverse view of the larynx. The laryngeal air column width (ACW) was defined as the width of air passed through the vocal cords as determined by US (the width of the acoustic shadow present at the level of the vocal cords) [10] (Fig. 1). ACW during endotracheal tube balloon cuff deflation and inflation over the respiratory cycles for three consecutive times, the averaged value was recorded. Both air column width ratio (ACWR) and air column width difference (ACWD) were recorded. ACWR was defined as ACW before extubation/ACW after intubation [11], while ACWD referred to ACW with the cuff deflated-ACW with cuff inflated at time of extubation [12].

After vocal cord ultrasonic examination, the upper tracheal rings were also examined in a transverse view while the patient is still in the same position. The probe was placed at the suprasternal notch for a transverse

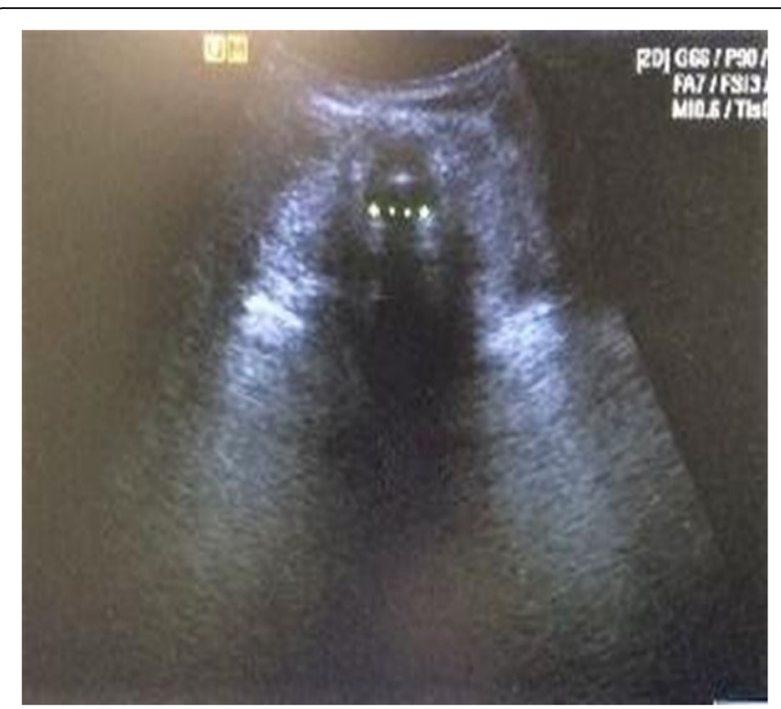

Fig. 1 Laryngeal ultrasound. The air column width (ACW) measured as the width of the acoustic shadow present at the level of the vocal cords (white line)

view where the trachea appears as an inverted U-shaped structure with smooth mucosal lining marked by airmucosa interface (Fig. 2) [13]. The transverse tracheal diameter was recorded. Also, any irregularity or loss of air-mucosa interface was reported.

\section{Multidetector CT chest (MDCT) and virtual bronchoscopy}

Patients were evaluated by 64-row MDCT scanner (Aquilion 64, Toshiba medical systems, Nasu, Japan). Patients were examined in a supine headfirst position with elevated arms and were scanned in a craniocaudal direction starting from the level of the nasal sinuses down to the upper abdomen.

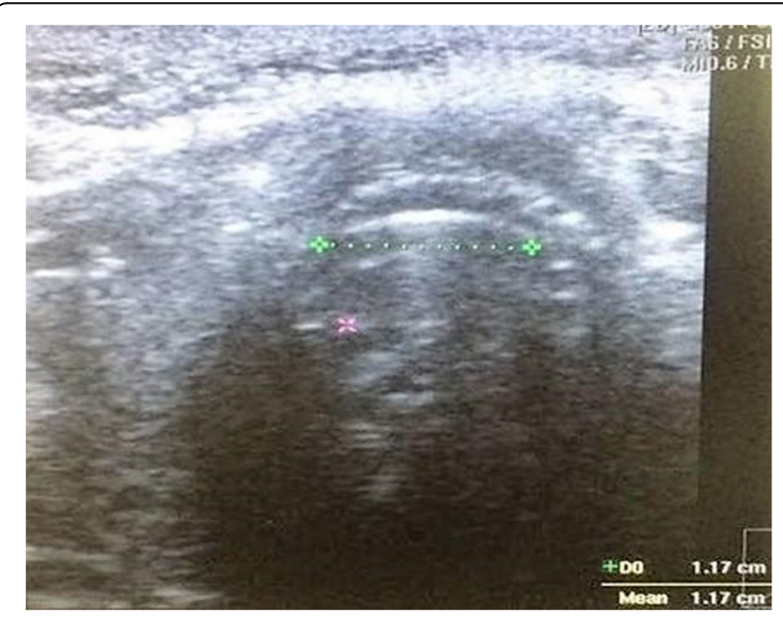

Fig. 2 Tracheal ultrasound. The trachea appears as an inverted Ushaped structure with smooth mucosal lining marked by air-mucosa interface and the transverse diameter of the trachea was measured at the level of suprasternal notch (dotted line) 
Axial CT imaging was transferred to an advantage independent workstation (Vitrea workstation) "Vitrea ${ }^{\bullet} 2$; Version 3.9" for computer post-processing. Postprocessing, chest multiplanar volume rendering (MPVR) images were collected at axial, sagittal, and coronal planes. Via the 3D shaded surface display and a flythrough examination of virtual lumen, an image of the $3 \mathrm{D}$ transparency lung volume rendering (TLVR) model of the tracheobronchial system was obtained. Transverse laryngeal and tracheal diameter was recorded by CT.

\section{Fiberoptic bronchoscopy (FOB)}

A light flexible bronchoscope (Pentax FB 18 V G11456, Japan) with $3.1 \mathrm{~mm}$ outer diameter attached to a light source (Pentax LH- 15011, Japan) and a digital camera (Pentax model 9215, Japan) was done for patients before extubation who had good oxygenation $\left(\mathrm{SO}_{2}>92 \%\right.$ on $\mathrm{FiO}_{2} \quad 0.4$ or less) with no history of bleeding tendency, liver or kidney disease, or old cerebrovascular stroke. During the procedure, fractional of inspired oxygen $\left(\mathrm{FiO}_{2}\right)$ should be increased to $100 \%$ and PEEP was set at $5 \mathrm{~cm} \mathrm{H}_{2} \mathrm{O}$. After the introduction of the bronchoscopy to the endotracheal tube and examination of the airways distal to the tube tip. The cuff balloon was gradually deflated and pulled up under vision to the level of the subglottic area. The balloon cuff site and inter trachea was carefully examined for inflammation, ulceration, or granulation tissue formation. Heart rate and oxygen saturation were continuously monitored during the procedure. Bronchoscopic findings were taken as gold standard results where US and CT were compared to it.

\section{Statistical analysis}

Statistical Package for the Social Sciences (SPSS) version 20 (produced by IBM SPSS Statistics for Windows, Version 20; Armonk, NY: IBM Corp.) software was used for analysis of results. Data were described using mean \pm standard deviation (SD) and frequencies accordingly if they are quantitative or qualitative respectively. MannWhitney test was used for comparison of results between stenosis and no stenosis groups. Spearman's correlation coefficient for the correlation between continuous variables was performed. $p<0.05$ was accepted as significant. The sensitivity and specificity of US and CT compared to FOB (as the gold standard test) were calculated by the following equations:

\footnotetext{
Sensitivity $=$ true positives $/($ true positive + false negative $) \times 100$.

Specicificity $=$ true negatives $/($ true negative + false positive $) \times 100$.

Positive predictive value $=$ true positives $/($ true positive + false positive $) \times 100$.

Negative predicitive value $=$ true negatives $/($ true negative + false negative $) \times 100$
}

\section{Results}

Demographic data of studied patients and possible risk factors for tracheal stenosis

We screened 167 intubated patients, 20 patients died before extubation. For technical issues, bronchoscopy and MDCT chest could not be done to all other patients. For results analysis, we included the 50 patients who were eligible to be investigated by MDCT chest, US, and FOB. Among them, 12 patients were found to have definite stenosis by FOB. Six patients (50\%) had subglottic stenosis, 3 patients (25\%) had endotracheal tube cuff site stenosis, one patient (8.33\%) had endotracheal tube tip stenosis, one patient $(8.33 \%)$ had tracheostomy stomal site stenosis, and one patient (8.33\%) had supraglottic stenosis.

Demographic data revealed significant older age in patients with stenosis than those without stenosis $(p=$ 0.036 ) with the mean age of patients with stenosis was 60.5 years. Patients with stenosis had also significantly higher BMI (29.50 vs. 24.05, $p=0.007)$ than patients who did not develop stenosis (Table 1 ).

The mean duration of mechanical ventilation was 14.75 days and ranged from 5 to 42 days which is significantly higher in patients who developed stenosis $(p=$ 0.048). Patients with stenosis also had significant higher rate of previous MV (41.7\% vs. $15.8 \%, p=0.016)$ and a higher rate of endotracheal tube change during the MV period as well $(41.7 \%$ vs. $5.3 \%, p=0.004)$ (Table 2$)$.

\section{Airway US and CT findings in patients with tracheal stenosis}

By US assessment, patients with stenosis showed significant lower ACW at weaning time $(5.8 \mathrm{~mm}$ vs. $6.4 \mathrm{~mm}, p$ $=0.021$ ) with significant lower ACWR and ACWD than patients without stenosis. Tracheal mucosa irregularity was also significantly reported in patients with stenosis than those without stenosis $(91.7 \%$ vs. $7.9 \%, p<0.001)$. By CT chest assessment, laryngeal width in patients with stenosis as well as tracheal diameter was significantly lower than patients without stenosis $(5.9 \mathrm{~mm}$ vs. 7.34 $\mathrm{mm}, p<0.001 ; 14.017 \mathrm{~mm}$ vs. $16.1 \mathrm{~mm}, p$ value $<0.001$ respectively) (Table 3 ).

Significant positive correlation was found between all ultrasound parameters and corresponding CT parameters. Figure 3 revealed a strong positive correlation between laryngeal width by CT and US $(r=0.798, p<0.001)$, while Fig. 4 revealed a strong positive correlation between tracheal diameter by CT and US $(r=0.714, p<0.001)$.

\section{Diagnostic yield of US and CT compared to FOB}

Compared to FOB results, the yield of MDCT chest for diagnosis of stenosis revealed that diagnostic accuracy was $97.4 \%$ with sensitivity $91.6 \%$ and specificity $100 \%$, while the yield of US detected by mucosal irregularity as a diagnostic tool for tracheal stenosis had a diagnostic 
Table 1 Demographic and clinical data of the study population $(N=50)$

\begin{tabular}{|c|c|c|c|}
\hline & Stenosis $(n=12)$ & No-stenosis $(n=38)$ & $p$ value \\
\hline Age (years) & & & $0.036^{*}$ \\
\hline Mean \pm SD & $62.50 \pm 12.66$ & $55.23 \pm 12.19$ & \\
\hline Sex, no. (\%) & & & 0.439 \\
\hline Male & $6(50)$ & $22(57.9)$ & \\
\hline Female & $6(50)$ & $16(42.1)$ & \\
\hline BMI & & & $0.007^{* *}$ \\
\hline Mean \pm SD & $29.50 \pm 6.26$ & $24.05 \pm 4.62$ & \\
\hline Smoking, no. (\%) & & & 0.892 \\
\hline Non-smoker & $8(47.1)$ & $16(42.1)$ & \\
\hline Active smoker & $4(23.5)$ & $11(28.9)$ & \\
\hline Ex-smoker & $5(29.4)$ & $11(28.9)$ & \\
\hline APACHE II score & & & 0.767 \\
\hline Mean \pm SD & $25.42 \pm 5.33$ & $25.84 \pm 4.89$ & \\
\hline Diagnosis, no. (\%) & & & 0.768 \\
\hline COPD & $6(50)$ & $18(47.4)$ & \\
\hline Non-COPD & $6(50)$ & $20(52.6)$ & \\
\hline Co-morbidities, no. (\%) DM & $4(33.3)$ & $14(36.8)$ & 0.556 \\
\hline HTN & $4(33.3)$ & $15(39.5)$ & 0.490 \\
\hline Renal impairment & $3(25)$ & $6(15.8)$ & 0.368 \\
\hline Hepatic diseases & $2(16.7)$ & $5(13.2)$ & 0.542 \\
\hline Old CVS & $2(16.7)$ & $2(5.3)$ & 0.240 \\
\hline
\end{tabular}

$B M I$ Body mass index, APACHE II score Acute physiology and chronic health evaluation II score, COPD Chronic obstructive pulmonary diseases, ILD Interstitial lung disease, OHS Obesity hypoventilation syndrome, DM Diabetes mellitus, HTN Hypertension, CVS Cerebrovascular stroke

accuracy of $94 \%$ with sensitivity $91.6 \%$ and specificity $88.9 \%$ (Table 4).

\section{Discussion}

Endotracheal intubation is a rapid, tolerable, and nonsurgical technique that achieves all the goals of airway management. However, the use of endotracheal intubation has produced a spectrum of upper airway complications that range in location from the nostril to the lower trachea, and in severity from pharyngitis to complete obstruction of the airway. Screening of postintubation stenosis can allow early diagnosis, early management of stenosis, and possible prevention of progress [1]. So, we aimed in this study to evaluate the validity of US as a bedside test for early diagnosis of postintubation stenosis and to compare laryngotracheal US to $\mathrm{CT}$ and $\mathrm{FOB}$ as the gold standard method. We also secondarily aimed to detect the incidence of post-

Table 2 MV data of the study population $(N=50)$

\begin{tabular}{|c|c|c|c|}
\hline & Stenosis $(n=12)$ & No-stenosis $(n=38)$ & $p$ value \\
\hline Duration of MV (days) & & & $0.048^{*}$ \\
\hline Mean \pm SD & $14.75 \pm 9.69$ & $10.29 \pm 3.31$ & \\
\hline Mode of MV, no. (\%) & & & 0.818 \\
\hline VC & $7(58.3)$ & $22(57.9)$ & \\
\hline PC & $2(16.7)$ & $9(23.7)$ & \\
\hline Dual & $3(25)$ & $7(18.4)$ & \\
\hline Previous intubation, no. (\%) & $5(41.7)$ & $6(15.8)$ & $0.016^{*}$ \\
\hline Endotracheal tube change during MV, no. (\%) & $5(41.7)$ & $2(5.3)$ & $0.004^{* *}$ \\
\hline Tracheostomy, no. (\%) & $1(5.9)$ & $3(7.9)$ & 0.141 \\
\hline
\end{tabular}

MV Mechanical ventilation, VC Volume control, $P C$ Pressure control *Statistically significant 
Table 3 Upper airway ultrasound and CT of the study population ( $N=50)$

\begin{tabular}{|c|c|c|c|}
\hline & Stenosis $(n=12)$ & No-stenosis $(n=18)$ & $p$ value \\
\hline \multicolumn{4}{|l|}{ Laryngeal ultrasound } \\
\hline ACW deflation at 1 st day $(\mathrm{mm})$ & & & 0.615 \\
\hline Mean \pm SD & $7.217 \pm 0.57$ & $7.418 \pm 0.71$ & \\
\hline ACW deflation at weaning $(\mathrm{mm})$ & & & $0.021^{*}$ \\
\hline Mean \pm SD & $5.808 \pm 0.78$ & $6.41 \pm 0.85$ & \\
\hline ACW inflation at weaning $(\mathrm{mm})$ & & & 0.631 \\
\hline Mean \pm SD & $5.283 \pm 0.68$ & $5.48 \pm 0.79$ & \\
\hline ACWR & & & $0.013^{*}$ \\
\hline Mean \pm SD & $0.803 \pm 0.06$ & $0.863 \pm 0.07$ & \\
\hline ACWD (mm) & & & $0.002^{* *}$ \\
\hline Mean \pm SD & $0.525 \pm 0.26$ & $0.932 \pm 0.39$ & \\
\hline \multicolumn{4}{|l|}{ Tracheal US } \\
\hline Tracheal diameter at $1 \mathrm{st}$ day $(\mathrm{mm})$ & & & 0.955 \\
\hline Mean \pm SD & $16.43 \pm 1.77$ & $16.45 \pm 1.062$ & \\
\hline Tracheal diameter at weaning $(\mathrm{mm})$ & & & 0.152 \\
\hline Mean \pm SD & $15.05 \pm 1.18$ & $15.73 \pm 1.28$ & \\
\hline Mucosal irregularity, no. & & & $<0.001^{* * *}$ \\
\hline (\%) Normal & $1(8.3)$ & $35(92.1)$ & \\
\hline Irregular & $11(91.7)$ & $3(7.9)$ & \\
\hline \multicolumn{4}{|l|}{ CT } \\
\hline \multicolumn{4}{|l|}{ Laryngeal width by $\mathbf{C T}(\mathrm{mm})$} \\
\hline Mean \pm SD & $5.9 \pm 0.67$ & $7.34 \pm 0.81$ & $<0.001^{* * *}$ \\
\hline Tracheal diameter by $\mathrm{CT}(\mathrm{mm})$ & & & $<0.001^{* * *}$ \\
\hline Mean \pm SD & $14.017 \pm 0.8 .5$ & $16.1 \pm 1.004$ & \\
\hline
\end{tabular}

ACW Air column width, ACWR Air column width ratio, ACWD Air column width difference *Statistically significant

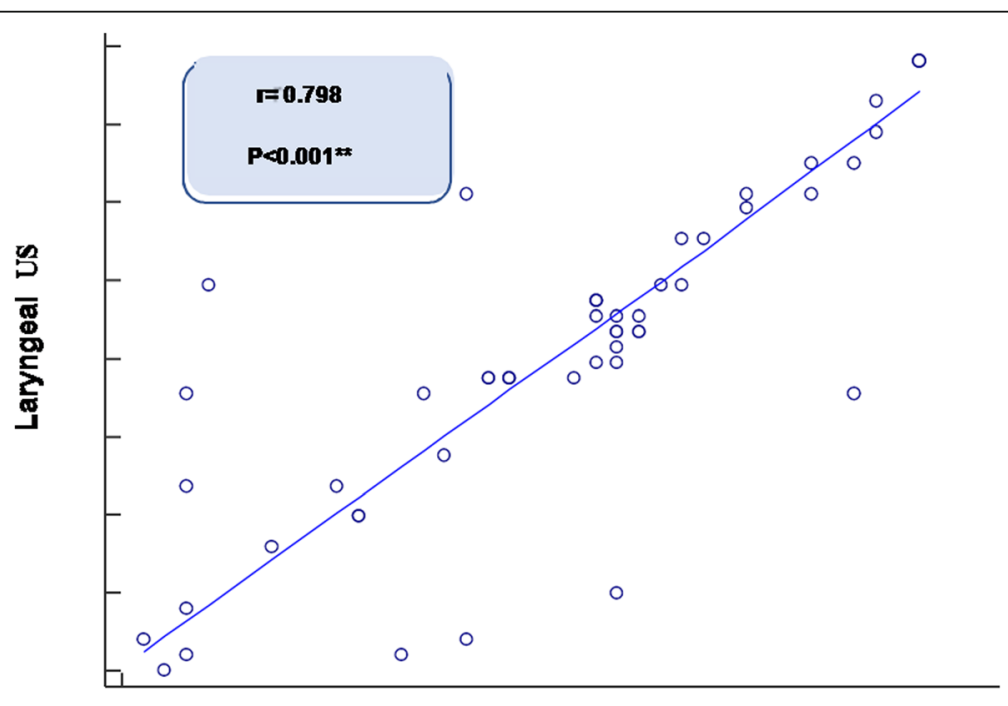

Laryngeal CT

Fig. 3 Correlation between CT laryngeal width and US laryngeal width $(r=0.798, p<0.001)$ 


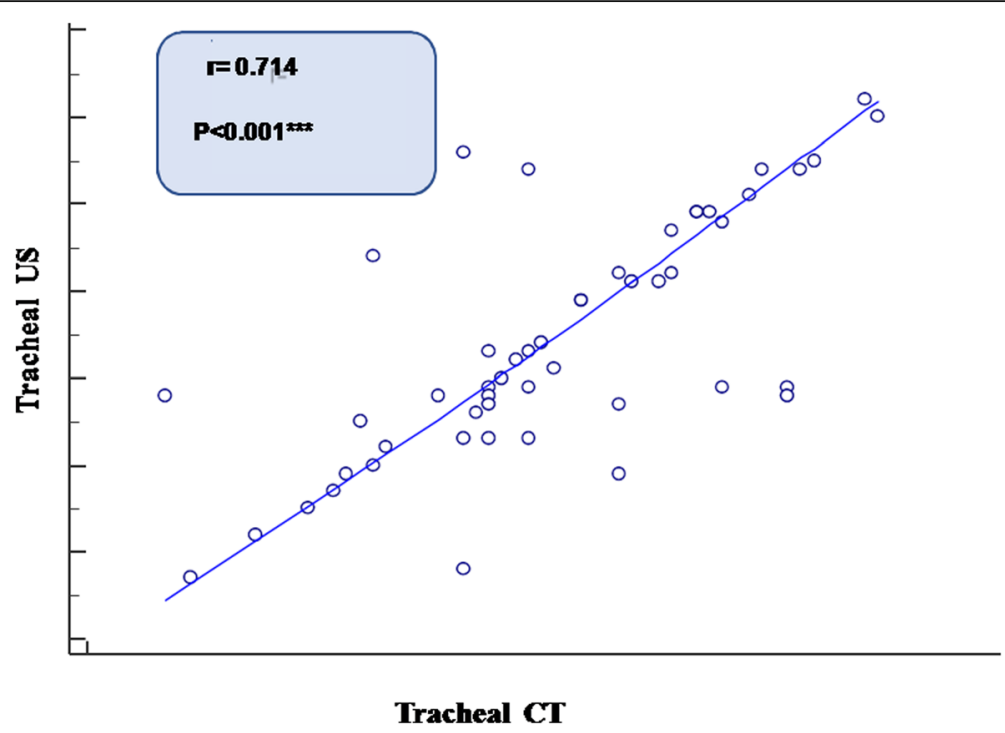

Fig. 4 Correlation between CT tracheal diameter and US tracheal diameter $(r=0.714, p<0.001)$

intubation stenosis, the most common site of postintubation stenosis, and possible risk factors for postintubation stenosis.

In this study, the incidence of post-intubation was $24 \%$ among all intubated patients included in this study. The incidence rate of tracheal stenosis following intubation and tracheostomy varies widely in previous literatures. It ranged from 6 to $21 \%$ [14] and 0.6 to 21\% [15]. A recent study performed in 5 hospitals in Iran; the incidence of post-intubation stenosis was 7\% [16]. This could be explained by the difference in the endotracheal tube type, different study designs, and durations. The most common site of stenosis was subglottic (50\%) followed by endotracheal tube cuff site stenosis (25\%) then endotracheal tube tip stenosis. Similarly Reddy and Sandeep [17] found that subglottis and proximal trachea were the most common sites for stenosis, followed by distal trachea, glottis, and supraglottis. On the other hand, endotracheal tube cuff site stenosis was used to present in one-third of the reported post-intubation cases [2, 18]. Age, obesity, longer duration of $\mathrm{MV}$, previous history of $\mathrm{MV}$, and more than once endotracheal tube change during the period of mechanical ventilation were found as possible risk factors for post-intubation stenosis. In previous studies, tracheal tube size, material of tube cuff

Table 4 Yield of CT and US mucosal examination in the diagnosis of post-intubation laryngotracheal stenosis

\begin{tabular}{llllll}
\hline & Sensitivity & Specificity & PPV & NPV & AI \\
\hline CT & $91.6 \%$ & $100 \%$ & $100 \%$ & $97.4 \%$ & $98 \%$ \\
US mucosal irregularity & $91.6 \%$ & $88.9 \%$ & $84.6 \%$ & $94.1 \%$ & $94 \%$
\end{tabular}

PPV Positive predictive value, NPV Negative predictive value, Al Accuracy index, US Ultrasound, CT Computed tomography
[19], female gender [20], obesity [21], and smoking [22] were possible risk factors of post-intubation stenosis.

By US assessment, patients with stenosis showed significant lower ACW at weaning time $(p=0.021)$ with significant lower ACWR and ACWD than patients without stenosis. These measured parameters (ACW, ACWR, and ACWD) were previously evaluated in the prediction of post-extubation stridor. Ding et al. [12], who to our knowledge, were the 1 st to report the ability of ultrasound to visualize the vocal cords and larynx and had shown that ACW and ACWD had some benefit for predicting laryngeal edema. Similarly, Sutherasan et al. [23] showed that ACWD is a predictor for laryngeal edema. Regarding the trachea, this study revealed a significant decrease in tracheal diameter estimated by US in patients with tracheal stenosis. There was only one previous study done to evaluate US in tracheal stenosis in which the tracheal wall thickness and diameter and cause of stenosis were evaluated in 6 patients with known stenosis of different pathologies. Moreover, ultrasound had the ability to identify the intrinsic tracheal disease as well as para-tracheal mass compressing the trachea [13].

Multi-detector CT with virtual bronchoscopy was a good modality for the diagnosis of post-intubation laryngotracheal stenosis [24]. This study found a strong positive correlation between laryngeal US and laryngeal CT measurements. Lakhal et al. [25] found a strong correlation between ultrasonography method to measure the smallest subglottic diameter and MRI measurements. ElAnwar et al.'s [26] study showed that US provides nearly full data about diameter, length, and nature of subglottic stenosis which was correlated to CT.

Compared to FOB as the gold standard for diagnosis of tracheal stenosis, the yield of mucosal irregularity by 
US as a diagnostic tool for laryngotracheal stenosis had diagnostic accuracy of $94 \%$ with $91.6 \%$ sensitivity and $88.9 \%$ specificity. El-Anwar et al.'s [26] study showed that US provides sensitivity of $88.5 \%$, specificity of $100 \%$, and accuracy of $91.7 \%$ for diagnosis of subglottic stenosis compared to endoscopic findings. CT showed a high diagnostic yield (98\%) with $91.6 \%$ sensitivity and 100\% specificity which agree with Taha et al. [27], who reported that MDCT with VB diagnosed $94 \%$ of lesions. To our knowledge, this is the first study to evaluate tracheal ultrasound in intubated MVpatients. It could be hypothesized that in the current study the relatively low diagnostic accuracy and specificity of tracheal US compared to CT despite its higher sensitivity explained by the fact that US provides a $2 \mathrm{D}$ image in which we examine only transverse diameter while the posterior wall of the trachea was not visualized due to air artifacts. Also, the tracheal US clarifies only upper 6 tracheal rings at suprasternal view while lower seated pathologies might be missed. On the other hand, MDCT could provide different views all along the airway.

\section{Limitation of the study}

First, generally, ultrasound is operator dependent. Moreover, laryngeal and tracheal ultrasound needs personal skills and experience. Second, a small number of patients enrolled in the study. So, we recommended that further studies are needed to evaluate laryngeal and tracheal US in larger samples of respiratory ICU patients during MV and in the post-extubation period.

\section{Conclusion}

Ultrasound is a bedside, safe, non-invasive tool. As it is highly sensitive, it could help in the detection of possible post-intubation laryngotracheal stenosis in critically ill MV patients.

\section{Abbreviations}

US: Ultrasound; MDCT: Multidetector computed tomography; MV: Mechanical ventilation; ICU: Intensive care unit; FOB: Fiberoptic bronchoscopy; BMI: Body mass index; ACW: Air column width; ACWR: Air column width ratio; ACWD: Air column width diameter; MPVR: Multiplanar volume rendering; TLVR: Transparency lung volume rendering

\section{Acknowledgements}

The authors thanks the residents and the nurses for their help during the study.

\section{Authors' contributions}

The authors have read and approved the manuscript. SF contributes to literature search, clinical studies, data analysis, manuscript preparation, and manuscript review. Professor AZ contributes to concepts, design of the study, and definition of intellectual content. Professor LS contributes to the definition of intellectual content, manuscript review, and takes responsibility of the integrity of the work as a whole. HME contributes to the definition of intellectual content and clinical studies. MK contributes to data acquisition, data analysis, and statistical analysis.

\section{Funding}

This research did not receive any specific grant from funding agencies in the public, commercial, or not-for-profit sectors.

\section{Availability of data and materials}

The datasets used or analyzed during the current study are available from the corresponding author on reasonable request.

\section{Ethics approval and consent to participate}

The study was approved by the Medical Ethics Committee of the Faculty of Medicine at Assiut University Hospital but no reference number available. An informed verbal consent was obtained from patient relatives before their inclusion in the study. The medical ethics committee of the faculty of medicine approved verbal consent.

\section{Consent for publication}

Not applicable.

\section{Competing interests}

The authors declare no financial or non-financial competing interest.

\section{Author details}

${ }^{1}$ Chest Department, Faculty of Medicine, Assiut University Hospital, Assiut, Egypt. ${ }^{2}$ Radiology Department, Faculty of Medicine, Assiut University, Assiut, Egypt.

Received: 26 July 2020 Accepted: 27 October 2020

Published online: 25 November 2020

\section{References}

1. Grillo HC, Donahue DM (1996) Postintubation tracheal stenosis. Chest Surg Clin N Am 6(4):725-731

2. Grillo HC, Donahue DM, Mathisen DJ, Wain JC, Wright CD (1995) Postintubation tracheal stenosis. Treatment and results. J Thorac Cardiovasc Surg 109(3):486-492

3. Stauffer J, Olson D, Petty T (1981) Complications and consequences of endotracheal intubation and tracheotomy. A prospective study of 150 critically ill adult patients. Am J Med 70(1):65-76

4. Tawfik KO, Houlton JJ, Compton W, Ying J, Khosla SM (2015) Laryngotracheal reconstruction: a ten year review of risk factors for decannulation failure. Laryngoscope. 125(3):674-679

5. Heyer CM, Nuesslein TG, Jung D, Peters SA, Lemburg SP, Rieger CH et al (2007) Tracheobronchial anomalies and stenoses: detection with low-dose multidetector CT with virtual tracheobronchoscopy-comparison with flexible tracheobronchoscopy. Radiology. 242:542-549

6. Gupta A, Gupta N, Sharma R (2018) Role of ultrasonography in difficult airway management. J Anaesthesiol Crit Care 1:2-11

7. Reddy PB, Punetha P, Chalam KS (2016) Ultrasonography - a viable tool for airway assessment. Indian J Anaesth 60:807-813

8. Osman A, Sum KM (2016) Role of upper airway ultrasound in airway management. J Intensive Care 4:52

9. Ezri T, Gewürtz G, Sessler DI, Medalion B, Szmuk P et al (2003) Prediction of difficult laryngoscopy in obese patients by ultrasound quantification of anterior neck soft tissue. Anaesthesia. 58:1111-1114

10. Pluijms WA, van Mook WN, Wittekamp BH, Bergmans DC (2015) Postextubation laryngeal edema and stridor resulting in respiratory failure in critically ill adult patients: updated review. Crit Care 19(1):295

11. Venkategowda PM, Mahendrakar K, Rao SM, Mutkule DP, Shirodkar CG, Yogesh H (2015) Laryngeal air column width ratio in predicting post extubation stridor. Indian J Crit Care Med 19(3):170-173

12. Ding LW, Wang HC, Wu HD, Chang CJ, Yang PC (2006) Laryngeal ultrasound: a useful method in predicting post-extubation stridor. A pilot study. Eur Respir J 27(2):384-389

13. Shih JY, Lee LN, Wu HD, Yu CJ, Wang HC, Chang YL et al (1997) Sonographic imaging of the trachea. J Ultrasound Med 16(12):783-790

14. Sarper A, Ayten A, Eser I, Ozbudak O, Demircan A (2005) Tracheal stenosis after tracheostomy or intubation: review with special regard to cause and management. Tex Heart Inst J 32(2):154-158

15. Esteller-More E, Ibanez J, Matino E, Adema JM, Nolla M, Quer IM (2005) Prognostic factors in laryngotracheal injury following intubation and/or tracheotomy in ICU patients. Eur Arch Otorhinolaryngol 262(11):880-883 
16. Farzanegan R, Farzanegan B, Zangi M, Golestani EM, Noorbakhsh S, Doozandeh TN et al (2016) Incidence rate of post-intubation tracheal stenosis in patients admitted to five intensive care units in Iran. Iran Red Crescent Med J 18(9):e37574

17. Sudarshan Reddy L, Sandeep L (2018) Study of laryngotracheal stenosis and its management in 25 cases. J Head Neck Spine Surg 2(2):5555-5582

18. Pearson FG, Andrews MJ (1971) Detection and management of tracheal stenosis following cuffed tube tracheostomy. Ann Thorac Surg 12(4):359-374

19. Mathias DB, Wedley JR (1974) The effects of cuffed endotracheal tubes on the tracheal wall. Br J Anaesth 46(11):849-852

20. McCaffrey TV (1992) Classification of laryngotracheal stenosis. Laryngoscope. 102:1335-1340

21. Nicolli EA, Carey RM, Farquhar D, Haft S, Alfonso KP, Mirza N (2017) Risk factors for adult acquired subglottic stenosis. J Laryngol Otol 131(3):264-267

22. Koshkareva Y, Gaughan JP, Soliman AM (2007) Risk factors for adult laryngotracheal stenosis: a review of 74 cases. Ann Otol Rhinol Laryngol 116(3):206-210

23. Sutherasan $Y$, Theerawit $P$, Hongphanut $T$, Kiatboonsri C, Kiatboonsri S (2013) Predicting laryngeal edema in intubated patients by portable intensive care unit ultrasound. J Crit Care 28(5):675-680

24. El-Naga HAE-RA, Abdelaziz M, Shawky M (2016) The role of multidetector CT virtual bronchoscopy in assessment of patients with laryngotracheal stenosis. J Otolaryngol-ENT Res 5(2):00135

25. Lakhal K, Delplace X, Cottier JP, Tranquart F, Sauvagnac X, Mercier C et al (2007) The feasibility of ultrasound to assess subglottic diameter. Anesth Analg 104(3):611-614

26. El-Anwar M, Amer H, Herzallah I, El-Gerby K (2014) Assessment of laryngeal ultrasound feasibility in evaluating subglottic stenosis. Med J Cairo Univ 82(2):33-37

27. Taha MS, Mostafa BE, Fahmy M, Ghaffar MK, Ghany EA (2009) Spiral CT virtual bronchoscopy with multiplanar reformatting in the evaluation of post-intubation tracheal stenosis: comparison between endoscopic, radiological and surgical findings. Eur Arch Otorhinolaryngol 266(6):863-866

\section{Publisher's Note}

Springer Nature remains neutral with regard to jurisdictional claims in published maps and institutional affiliations.

\section{Submit your manuscript to a SpringerOpen ${ }^{\circ}$ journal and benefit from:}

- Convenient online submission

- Rigorous peer review

- Open access: articles freely available online

- High visibility within the field

- Retaining the copyright to your article

Submit your next manuscript at $\boldsymbol{\nabla}$ springeropen.com 